cause is external compression due to coma induced by drugs or alcohol. Awareness of this condition is important, as leg weakness in a patient recovering from coma may be misinterpreted as being due to an intracranial lesion. Sciatic neuropathy occurring as an intraoperative pressure palsy or during prolonged immobilisation in bed is less well recognised than pressure palsies of the ulnar and peroneal nerves, but our findings illustrate that the sciatic nerve is also vulnerable in these situations.

Six patients developed sciatic neuropathy after hip surgery, particularly hip replacement. In one centre this has been reported as occurring in $0.5 \%$ of hip replacement operations. ${ }^{3}$ The nerve may be damaged by the heat of the setting cement, the cement itself, or by retraction. These neuropathies have been said to have a good prognosis for recovery, and our findings confirm this.

${ }^{1}$ Seddon H. Surgical disorders of the peripheral nerves. Edinburgh: Churchill Livingstone, 1975.

${ }^{2}$ Sunderland S. Nerves and nerve injuries. Edinburgh: Churchill Livingstone, 1978.

${ }^{3}$ Weber ER, Daube JR, Coventry MB. Peripheral neuropathies associated with total hip arthroplasty. $\mathcal{F}$ Bone foint Surg 1976;58A:66-9.

(Accepted 17 fune 1983)

Department of Neurology and Neurosurgery, McGill University, The

Montreal General Hospital, Montreal, Quebec H3G 1A4, Canada J D STEWART, MB, FRCP(C), associate professor

E ANGUS, MD, resident

D GENDRON, MD, FRCP(C), resident

Correspondence to: Professor J D Stewart.

\section{Seasonal variation in incidence of brachial and femoral emboli}

The heart is the most common source of brachial and femoral emboli. ${ }^{1}$ Rheumatic endocarditis of mitral or aortic valves (particularly associated with atrial flutter or atrial fibrillation), mural thrombi secondary to myocardial infarction, and prosthetic valves are often predisposing factors. I examined the case records of patients in whom peripheral arterial embolus had been diagnosed to compare the incidences of brachial and femoral emboli and to determine whether seasonal variation occurred.

\section{Patients, methods, and results}

Analysis was made of 127 consecutive patients (mean age 70.6 (range 41-92) years) presenting with brachial or femoral embolus referred to consultant surgeons with a specialist interest in vascular surgery on one unit of the Royal Infirmary of Edinburgh during the 11 years to 17 April 1983. Femoral embolus was significantly more common than brachial embolus ( 88 patients $v 39 ; \mathrm{p}<0.001$ ). There was no relation to sex (59 men, 68 women).

The table shows the seasonal distribution of systemic embolus, with a peak incidence during the winter months and a trough in summer. Comparison of the periods October to March with April to September yielded a significant difference $\left(\chi^{2}=8.574, \mathrm{df}=1, \mathrm{p}<0.01\right)$. The hypothesis of a constant incidence throughout the year was not reasonable $\left(\chi^{2}=29 \cdot 19\right.$, $\mathrm{df}=11, \mathrm{p}=0.0021$ ), but when the logarithms of the observed counts were submitted to regression on a sine (month) and cosine (month) scale jointly on a 12 month cycle assuming Poisson type errors, goodness of fit was satisfactory $\left(\chi^{2}=13 \cdot 46, \mathrm{df}=9, \mathrm{p}=0 \cdot 14\right)$.

Monthly distribution of brachial and femoral emboli over 11 years

\begin{tabular}{lccc}
\hline & Brachial embolus & Femoral embolus & Total \\
\hline July & 2 & 7 & 9 \\
August & 2 & 3 & 5 \\
September & 2 & 8 & 10 \\
October & 2 & 11 & 13 \\
November & 1 & 9 & 17 \\
December & 6 & 11 & 22 \\
January & 7 & 15 & 8 \\
February & 2 & 6 & 10 \\
March & 4 & 6 & 6 \\
April & 8 & 6 & 3 \\
May & 2 & 4 & 127 \\
June & 1 & 2 & \\
\hline Total & 39 & 88 &
\end{tabular}

\section{Comment}

The distribution of systemic emboli may be related to external temperature. Increased mortality from ischaemic heart disease and stroke during the winter is well documented. ${ }^{2-4}$ Although incidence cannot be equated with mortality (which may change differentially), a similar seasonal influence is seen with recordings of systolic and diastolic blood pressure. ${ }^{2}$

Bull et al investigated the relation of air temperature to various chemical, haematological, and haemostatic variables. ${ }^{5}$ They concluded that there was no association with either routine haematological or clinical chemical variables. The correlation between increased antithrombin III concentrations and higher temperatures (and consequently an increased tendency to thrombosis at lower temperatures) is consistent with increased mortality from vascular accidents at lower temperatures. This is countered, however, by an inverse relation between fibrinolytic activity and temperature-that is, increased fibrinolysis at lower temperatures.

In conclusion, a significant seasonal variation was found in the incidence of brachial and femoral emboli. The reasons for this remain uncertain although there may be a correlation with external temperature.

I thank Mr B Nolan for permission to report these figures, Dr M Tweedie for statistical advice, and Miss $M$ Corr for typing the manuscript.

1 Strandness DE. Vascular diseases of the extremities. In: Thorn GW, Adams RD, Braunwald E, Isselbacher KJ, Petersdorf RG, eds. Harrison's principles of internal medicine. 8th ed. Tokyo: McGraw-Hill Kogakusha, 1977:1322.

${ }^{2}$ Brennan PJ, Greenberg G, Miall WE, Thompson SG. Seasonal variation in arterial blood pressure. Br Med f 1982;285:919-23.

${ }^{3}$ Bull GM, Morton J. Environment, temperature and death rates. Age Ageing 1978;7:210-24.

${ }^{4}$ Bull GM. Meteorological correlates with myocardial and cerebral infarction and respiratory disease. British fournal of Preventive and Social Medicine 1973;27:108-13.

${ }^{5}$ Bull GM, Brozonic M, Chakraborti R, et al. Relationship of air temperature to various chemical, haematological and haemostatic variables. $\mathcal{f}$ Clin Pathol 1979;32:16-20.

(Accepted 28 fune 1983)

Vascular Surgical Unit, Royal Infirmary, Edinburgh EH3 9YW

CHARLES V CLARK, BSC, MB, senior house officer

Correspondence to: Dr C V Clark, Research Fellow, Department of Ophthalmology (University of Liverpool), St Paul's Eye Hospital, Old Hall Street, Liverpool L3 9PF.

\section{Wheelchairs used by old people}

Two thirds of the 200000 wheelchairs in England and Wales are used by people over retirement age. ${ }^{1}$ Most wheelchairs have inflatable tyres, and the brakes work by a plate pressing against the tyre. If the tyre is flat the brake will not function effectively and propelling and steering the wheelchair may be difficult. If the brake does not work properly getting in and out of the wheelchair may be hazardous. We have observed that many wheelchairs used by elderly people have inefficient brakes and flat tyres.

\section{Patients, methods, and results}

We interviewed 61 elderly users of wheelchairs in their homes; 55 of them were attending Sherwood Geriatric Day Hospital. The main disabilities necessitating provision of a wheelchair were stroke (34 patients $(57 \%)$ ), arthritis (eight $(13 \%)$ ), and amputation (eight $(13 \%)$ ). Thirty three of the patients were women.

Fifty nine of the wheelchairs were on loan from the Department of Health and Social Security. Three quarters were self propelling, general purpose wheelchairs, the remainder being attendant propelled, transit wheelchairs. Two wheelchairs had solid tyres; the rest had pneumatic tyres.

We asked the patients to demonstrate how to operate the brakes and to produce a pump and show us how to use it. We assessed mental function using a 10 point memory questionnaire. Examination of the wheelchair included inspection of tyres and brakes. We considered tyres to be inadequately inflated if the brake action was compromised by lack of inflation. We found one puncture, and 18 other wheelchairs had flat tyres. Of the 
patients using these, 16 either failed to appreciate that the tyres were flat or did not know how to inflate them. Their mental function test score did not differ from that of those whose tyres were fully inflated. Altogether 15 women and four men did not know how to pump up tyres, and 11 patients did not possess a pump. Two wheelchairs had a different type of valve connection on each wheel; the users were not aware that the pump could be adapted to both types of valve. Fourteen wheelchairs had primary brake defects (six of these also had flat tyres). In 10 cases the brake spring was too weak and in four it was too stiff.

\section{Comment}

Most wheelchairs have inflatable tyres because compressed air is light and ensures a comfortable ride. ${ }^{2}$ In Britain the wheelchair brake mechanism requires the brake lever to be pushed or pulled so that the brake plate presses against the outer rim of the tyre. Tyre and brake problems are the commonest reasons why wheelchair users request help from appliance centres. Fenwick found that $12 \%$ of wheelchair users had had tyres repaired in the previous year. ${ }^{1}$ Neither of the major surveys of patients in wheelchairs, however, mentioned the problem of flat tyres. ${ }^{13}$

The power required to propel and manoeuvre a wheelchair is considerable, ${ }^{4}$ and if the tyres are flat even more effort is needed. One third of our elderly patients had wheelchairs with inadequately inflated tyres, which may render patients housebound. How many wheelchair users would become more mobile if their tyres were correctly inflated has yet to be determined.

Some wheelchair users have no pump, and many, especially elderly women, do not know how to use one. We suggest that as part of their general instructions users of wheelchairs are shown how to use a pump. Inspection of tyres and brakes should be a routine part of the assessment by those taking part in community care of immobile elderly patients using wheelchairs; community nurses and doctors might consider carrying a pump on their rounds.

We are grateful to the consultants at Sherwood Hospital for allowing us to study their patients. We thank Mr G S Trenchard and Dr M L Rajakaruna of the artificial limb and appliance centre, Nottingham, for their helpful advice and Mrs G Marson for typing the manuscript.

${ }^{1}$ Fenwick D. Wheelchairs and their users. London: HMSO, 1977.

2 Bossingham DH. Wheelchairs and appliances. Clin Rheum Dis 1981;7: 395-415.

${ }^{3}$ Harris A, Cox E, Smith CRW. Handicapped and impaired in Great Britain. Part 1. London: HMSO, 1971.

- Hildebrandt G, Voight ED, Behn D, Berender B, Kruger J. Energy costs of propelling wheelchairs at various speeds: cardiac response and effect of steering accuracy. Arch Phys Med Rehabil 1970;18:23-9.

(Accepted 22 fune 1983)

Department of Health Care of the Elderly, Sherwood Hospital, Nottingham NG5 1PD

E HAWORTH, MRCP, senior registrar

R H POWELL, DIPCOT, occupational therapist

G P MULLEY, MRCP, consultant in geriatric medicine

Correspondence to: Dr G P Mulley.

\section{Use of home insemination in programmes of artificial insemination with donor semen}

Artificial insemination with donor semen (AID) is increasingly being used to help the childless and some of those couples who are at risk of producing children with genetic disease. ${ }^{1}$ Public knowledge of the service has become widespread, with most clinics reporting an increased demand and many now having waiting lists that are considerably larger than they would prefer. In addition, some couples find attending a hospital clinic stressful, which may be a factor in their inability to achieve a pregnancy. This is particularly true of clinics that serve a wide catchment area. (The clinic at this hospital receives women from a large metropolitan county as well as other parts of central England and Wales.)
In a pilot study we circumvented this problem by teaching couples to inseminate themselves and providing portable liquid nitrogen refrigerators for either home treatment or treatment by family practitioners. This service has been reasonably successful and we report here the results.

\section{Patients, methods, and results}

Couples were referred from the AID clinic at Birmingham Maternity Hospital or directly from an interested family doctor. In five cases the male partner presented with azoospermia, and the remaining two with oligozoospermia. All of the women (age range 27-36 years) had had several unsuccessful cycles of insemination at the hospital clinic and had had tubal patency established by laparoscopy and hydrotubation. Three had begun clomiphene while attending the hospital clinic, in one case to control irregular cycles and in the other two on an empirical basis. Most lived at least one hour's drive from the hospital, and two had to travel for between four and five hours for each visit. Another had had a previous pregnancy after artificial insemination elsewhere and found that even short journeys with a toddler were difficult.

After being accepted into the programme couples attended the clinic at about the time of ovulation for instruction in the use of equipment and the assessment of the signs of ovulation. Two women were inseminated by their family doctors, who were provided with full written instructions. Donor semen was frozen in $0.25 \mathrm{ml}$ straws $^{2}$ and kept in a large storage bank until required. Insemination was taught using either reusable insemination guns (IMV, L'Aigle, France) designed to hold the semen straws or disposable mucus collection syringes (Rocket, London). The partner was taught to inseminate $0.5 \mathrm{ml}$ semen into the cervix after exposing it with a stainless steel Cusco speculum, which was washed after each use. Insemination was carried out on two or three consecutive days at around the expected time of ovulation. No straws were ever returned.

Portable liquid nitrogen refrigerators (DX2AR, L'Air Liquide) capable of holding the straws frozen for 12-14 days were supplied three or four days before ovulation was expected. Elementary precautions in the handling of these refrigerators assured that they presented no particular hazard. Each cost about $£ 250$, and couples were offered the option of buying their own or using one from the clinic for the same monthly cost $(£ 25)$ as hospital artificial insemination.

Of the seven women who started treatment, three became pregnant after one, three, and three cycles of treatment, two of these delivered safely, and the third pregnancy was continuing. Two women decided to abandon treatment (after eight and four cycles of treatment) in favour of adoption. One patient was continuing with treatment after five cycles, while the seventh patient chose to move to another centre to have in vitro fertilisation and embryo transfer with donor semen after five unsuccessful home in seminations and 10 cycles of unsuccessful insemination at the hospital All three pregnancies occurred in women who had had unsuccessful attempts at the hospital clinic (with six, four, and five cycles of treatment respectively).

\section{Comment}

Insemination with donor semen either at home or by a family doctor may be a practical method of achieving a pregnancy in some infertile couples. Most couples learnt the technique very quickly and had no problems with the equipment. The general practitioners who participated also found the treatment interesting and easy to undertake.

Insemination in the evening, before going to sleep, might be more successful in achieving a pregnancy. The technique reduces strain on clinic resources and appears to be acceptable to some infertile couples, particularly since it permits more participation of the partner.

1 Newton JR. Current status of AI in clinical practice. In: Artificial in semination: proceedings of Fourth Study Group of the Royal College of Obstetricians and Gynaecologists. London: RCOG, 1976:25-41.

${ }^{2}$ Richardson DW. Techniques of sperm storage. In: Artificial insemination proceedings of Fourth Study Group of the Royal College of Obstetrician and Gynaecologists. London: RCOG, 1976:97-125.

(Accepted 21 fune 1983)

Department of Obstetrics and Gynaecology, Birmingham Maternity Hospital, Queen Elizabeth Medical Centre, Edgbaston, Birmingham B15 2TG

EILEEN A MCLAUGHLIN, BSC, technician

PETER D BROMWICH, MRCOG, lecturer

ANNA M MACKEN, fertility clinic manager

ANDREW P WALKER, BSC, research technician

JOHN R NEWTON, MD, FRCOG, professor

Correspondence to: Ms Eileen McLaughlin. 